\title{
Stent and leaflet stresses in 26-mm, third-generation, balloon-expandable transcatheter aortic valve
}

Yue Xuan, PhD, ${ }^{a}$ Danny Dvir, MD, ${ }^{\mathrm{b}}$ Zhongjie Wang, PhD, ${ }^{\mathrm{a}}$ Trek Mizoguchi, BS, ${ }^{\mathrm{a}}$ Jian Ye, MD, Julius M. Guccione, $\mathrm{PhD},{ }^{\mathrm{a}}$ Liang Ge, $\mathrm{PhD},{ }^{\mathrm{a}}$ and Elaine E. Tseng, $\mathrm{MD}^{\mathrm{a}}$

\section{ABSTRACT}

Objectives: Transcatheter aortic valve replacement has proven successful in treating intermediate-risk, high-risk, and inoperable patients with severe aortic stenosis. Third-generation, balloon-expandable transcatheter aortic valves were developed with an outer sealing skirt to reduce paravalvular leakage. As transcatheter aortic valve replacement use expands, long-term durability questions remain. Valve design influences durability, where regions of increased leaflet stress are vulnerable to early degeneration. However, third-generation transcatheter aortic valve stresses are unknown. Our goals were to determine the stent and leaflet stresses of third-generation, balloon-expandable transcatheter aortic valves.

Methods: The commercial 26-mm Edwards SAPIEN 3 valve (Edwards Lifesciences, Inc, Irvine, Calif) underwent high-resolution micro-computed tomography scanning to develop a precise 3-dimensional geometric mesh of the stent and valve. Leaflet material properties were obtained from surgical bioprostheses, and stent material properties were based on cobalt-chromium. Simulations of systemic pressure loading were performed, and stress was calculated using finite element analyses.

Results: At diastole, maximum and minimum principal stresses on transcatheter aortic valve leaflets were $2.7 \mathrm{MPa}$ and $-0.47 \mathrm{MPa}$, respectively. Peak leaflet stresses were observed at upper leaflet commissures, at their connection to the stent. Maximum and minimum principal stresses for the stent were $38.2 \mathrm{MPa}$ and $-44.4 \mathrm{MPa}$, respectively, at $80 \mathrm{~mm} \mathrm{Hg}$ and were located just below the commissural stent.

Conclusions: Stress analysis of the 26-mm SAPIEN 3 valve using exact geometry from high-resolution scans demonstrated that peak stresses for both transcatheter aortic valve stent and leaflets were present at commissural tips where leaflets were attached. These regions would be most likely to initiate degeneration. The Dacron skirt had minimal effect on stresses on leaflets and stent. (J Thorac Cardiovasc Surg 2019;157:528-36)

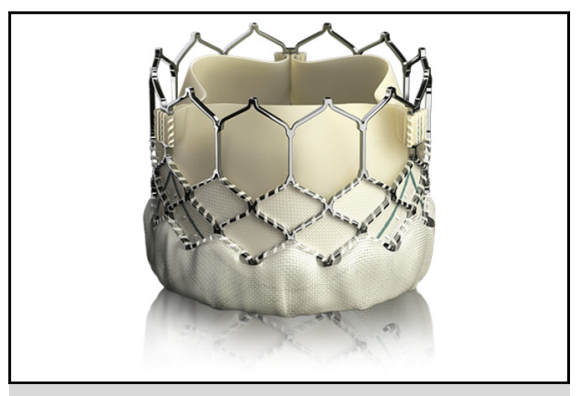

SAPIEN 3 valve (Edwards Lifesciences, Inc, Irvine, Calif).

Central Message
The current-generation SAPIEN 3 valve
(Edwards Lifesciences, Inc, Irvine, Calif) has
peak stresses at commissures and sutured
areas below, which may initiate eventual
bioprosthetic calcification and degeneration.
Perspective
Durability is a concern as transcatheter valves
move toward lower-risk younger patients.
Stress analyses are important for evaluating
relative durability compared with transcatheter
or surgical bioprostheses. We showed that peak
leaflet stresses in the current-generation
SAPIEN 3 valve (Edwards Lifesciences, Inc,
Irvine, Calif) occurred at leaflet commissures
at stent attachment sites, suggesting regions
prone to initiating degeneration.

See Editorial page 537.

See Editorial Commentary page 538.
Transcatheter aortic valve replacement (TAVR) has proven effective for treating severe aortic stenosis (AS) in intermediate- and high-risk surgical patients and inoperable

From the a Department of Surgery, University of California San Francisco and San Francisco VA Medical Centers, San Francisco, Calif; ${ }^{\mathrm{b}}$ Division of Cardiology, University of Washington, Seattle, Wash; and ${ }^{\mathrm{c} D i v i s i o n}$ of Cardiovascular Surgery, St Paul's Hospital and Vancouver General Hospital, Vancouver, British Columbia, Canada.

Funded by the University of California Proof of Concept Grant 246590, National Institutes of Health, R01HL119857, and American Heart Association 16POST31420013

Read at the Transcatheter Cardiovascular Therapeutics, Washington, DC, October 29 to November 2, 2016. patients. $^{1-3}$ The third-generation, balloon-expandable transcatheter aortic valve (TAV) SAPIEN 3 (Edwards Lifesciences, Inc, Irvine, Calif) was introduced commercially

Received for publication Sept 28, 2017; revisions received April 12, 2018; accepted for publication April 23, 2018; available ahead of print July 3, 2018.

Address for reprints: Elaine E. Tseng, MD, San Francisco VA Medical Center,

500 Parnassus Ave, Suite 405W, Box 0118, San Francisco, CA 94143-0118

(E-mail: Elaine.Tseng@ucsf.edu).

0022-5223/\$0.00

Published by Elsevier Inc. on behalf of The American Association for Thoracic Surgery

https://doi.org/10.1016/j.jtcvs.2018.04.115 

Abbreviations and Acronyms
AS $=$ aortic stenosis
$\mathrm{FE} \quad=$ finite element
FEA = finite element analysis
PET = polyethylene terephthalate
$\mathrm{PVL}=$ paravalvular leakage
SAVR = surgical aortic valve replacement
$\mathrm{TAV}=$ transcatheter aortic valve
$\mathrm{TAVR}=$ transcatheter aortic valve replacement

Scanning this QR code will take you to a supplemental video for the article.

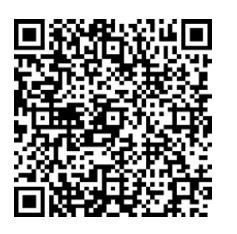

in January 2014 in Europe and in June 2015 in the United States. The SAPIEN 3 was the first TAVR device to receive US Food and Drug Administration approval for the expanded indication to intermediate-risk surgical patients with severe symptomatic AS. A key improvement in valve design over prior second-generation SAPIEN XT was inclusion of an outer polyethylene terephthalate (PET) sealing cuff at the base of the stent to significantly reduce paravalvular leakage (PVL). In addition to the standard 23-mm, 26-mm, and 29-mm sizes, a 20-mm diameter SAPIEN 3 became available for smaller annulus sizes and valve-in-valve implantation. Major alterations in stent configuration also occurred for the SAPIEN 3, which carried important clinical implications: (1) a significantly reduced profile for the crimped valve that allowed insertion within a $14 \mathrm{~F}$ or $16 \mathrm{~F}$ expandable sheath, (2) much larger cells distally to allow easier access for future coronary catheterization through the cell struts, and (3) an increase in overall stent length. ${ }^{4}$ Changes in stent configuration revolutionized vascular access for TAVR to allow routine transfemoral percutaneous access.

Concerns regarding TAVR durability have not been a major concern for the original clinical trials involving high-risk and inoperable patients who were typically octagenarians. ${ }^{5-9}$ However, as lower-risk younger patients become enrolled, the question of TAVR durability rises to the forefront. The Placement of Aortic Transcatheter Valves randomized trial 3 has been recruiting patients since April 2016 to test the safety and efficacy of SAPIEN 3 in low-risk surgical patients with AS. Valve design affects long-term durability. Regions of increased leaflet stresses correlate with areas of calcific degeneration and tearing. ${ }^{10-15}$ Therefore, understanding TAV leaflet stresses is important for determining relative durability of TAVs compared with other devices or bioprostheses. We have previously used finite element analysis (FEA) to examine leaflet stresses in the firstgeneration Edwards SAPIEN and second-generation SAPIEN XT valves. ${ }^{16,17}$ FEA is an established method to determine essential data about complicated biological systems that would otherwise be impossible to directly measure in vivo. FEA in physiologic studies is particularly valuable when used to estimate device durability by determining stresses and failure modes. Finite element (FE) models require accurate 3-dimensional geometry in zero-pressure state, detailed assembly, material properties, and physiologic loading conditions. Because of the important changes altering valve design, stresses on the most recent third-generation, balloon-expandable TAV are unknown. The goal of this study was to determine TAV stent and leaflet stresses in a $26-\mathrm{mm}$, third-generation Edwards SAPIEN 3 valve.

\section{MATERIALS AND METHODS}

The commercial 26-mm Edwards SAPIEN 3 (external diameter $25.8 \mathrm{~mm}$, height $20 \mathrm{~mm}$ ) was obtained. TAV assembly consisted of 4 components: bovine pericardial leaflets, cobalt-chromium stent, Dacron covering, and outer PET sealing skirt. Physical measurements were taken, and suture connections between different components were studied to enable accurate modeling of the assembly with its connections. Overview of this process to determine TAV stress distribution includes (1) development of TAV mesh using 3-dimensional geometry; (2) FEA using FE explicit solver; and (3) postprocessing and data analysis to determine stresses on leaflets and stent.

\section{SAPIEN 3 Transcatheter Aortic Valve Mesh Generation}

The SAPIEN 3 (26 mm) was imaged with a desktop cone-beam micro-computed tomography scanner (microCT-40; Scanco Medical AG, Baseldorf, Switzerland) in different orientations, including along the short axis for leaflet and long axis for stent reconstruction, and intensities to distinguish stent and leaflet geometries. Scan settings used were as follows: $\mathrm{X}$-ray energy $=45 \mathrm{kVp}, \mathrm{X}$-ray current $=200 \mu \mathrm{A}$, filter $=0.5 \mathrm{~mm}$ aluminum, field of view $=50 \mathrm{~mm}$, voxel size $=50 \mu \mathrm{m}$, and integration time $=200 \mathrm{~ms}$. High-resolution Digital Imaging and Communications in Medicine radiologic images (voxel size $50 \times 50 \times 50 \mu \mathrm{m}$ ) were imported into MeVisLab, an open source surface reconstruction software (http:// www.mevislab.de/). Digital Imaging and Communications in Medicine files were scanned individually to separate TAV stent versus leaflets materials to obtain the most accurate representation of their respective geometries. Stent and leaflet surfaces were combined using suture lines. The reconstructed surface was then imported into GeoMagic Design (3D Systems, Rock Hill, SC), where the geometries were created and refined (Figure 1,B). The finalized surface was then imported into Truegrid (XYZ Scientific Applications, Pleasant Hills, Calif) to generate a volume mesh with accurate size and thickness ex vivo. The total number of elements used was 20,988 for leaflets and 6167 for stent, 4320 for Dacron, and 4272 for skirt (Figure 1,C).

\section{Finite Element Analyses}

The SAPIEN 3 uses leaflets made of specially treated bovine pericardium to resist calcification, and that proprietary process is the same as for corresponding surgical Carpentier-Edwards pericardial valves (Edwards Lifesciences, Inc). We previously performed biaxial stretch testing of surgical bovine pericardial valves (Edwards Lifesciences, Inc) to determine material properties of TAV leaflets, to avoid destroying leaflets of the 26-mm SAPIEN 3. ${ }^{18}$ The methods of biaxial stretching 


Xuan et al

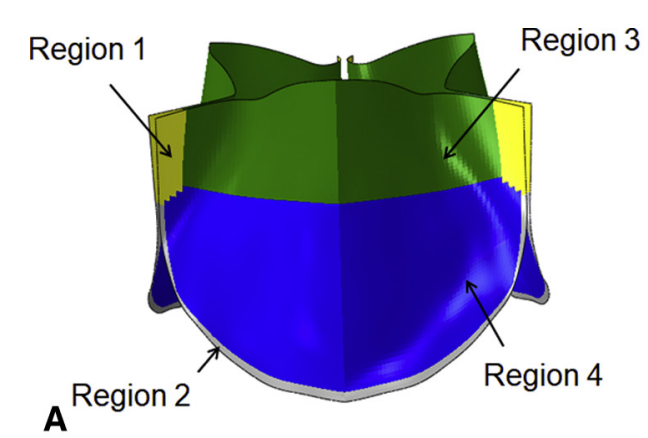

B
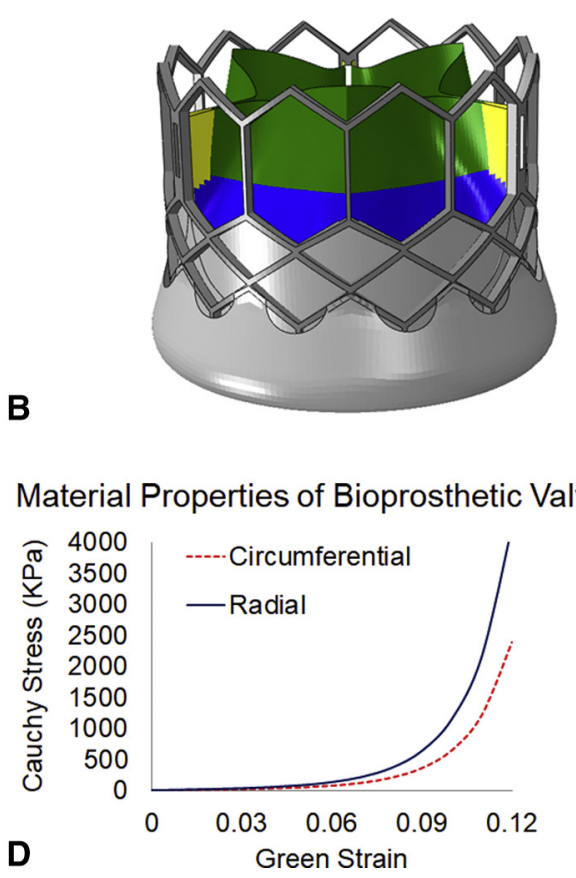

FIGURE 1. A, Subregions of the SAPIEN 3 (Edwards Lifesciences, Inc, Irvine, Calif) leaflet. B, Micro-computed tomography scanned geometry of leaflets. C, Mesh of the leaflets, stent, and skirt based on micro-computed tomography scanned images. D, Material property of bioprosthetic leaflets.

and the hyperelastic material model have been described. ${ }^{19}$ Averaged leaflet material properties from 12 bioprosthetic valves (35 leaflets) were used in this study, and the stress-strain curve of the averaged leaflet material property is presented in Figure 1, D.

FE simulations were performed using ABAQUS solver (Dassault Systems, Waltham, Mass). Stent geometry was modeled using 3-dimensional brick elements, whereas leaflet geometry was modeled using nonlinear shell elements. Mesh convergence studies were performed to determine the ideal mesh size for the balance of cost and accuracy. Contact definitions between leaflets and between leaflet and stent were investigated to choose one most accurately representing the overall behavior. Leaflet nodes were connected to the stent using a "TIE" contact (coefficient of friction value 0.1). TAV leaflet geometries were sutured to Dacron at the bottom and tied to stent geometry at the top. TAV leaflet mesh was subdivided into 4 distinct regions to study stress distribution due to pressure loading: (1) upper commissure, (2) lower commissure, (3) upper free leaflet region, and (4) lower leaflet belly region (Figure 1,A).

Simulations were performed to determine TAV stresses based on arterial loading conditions on commercial TAV without crimping and balloon expansion. Pressure loading was applied to outer surfaces of leaflets and stent to 80 and $120 \mathrm{~mm} \mathrm{Hg}$ with quasi-static loading conditions. Diastole results in highest pressure differential between aortic and left ventricular pressure; therefore, closed leaflet configurations were analyzed to assess leaflet stresses. Boundary conditions were applied to the stent to prevent any shifting of the stent. To simulate the deployed geometry, the stent was pulled along the radial direction to reach the desired diameter of $24 \mathrm{~mm}, 25 \mathrm{~mm}$, and $26.5 \mathrm{~mm}$, respectively.

\section{RESULTS}

Maximum and minimum principal stresses for the entire leaflet assembly, as well as each TAV component, were determined at 80 and $120 \mathrm{~mm} \mathrm{Hg}$. High stress concentration locations were determined. Maximum principal stresses for the SAPIEN 3 stent were $38.2 \mathrm{MPa}$ and $57.3 \mathrm{MPa}$ at 80 and $120 \mathrm{~mm} \mathrm{Hg}$, respectively (Figure 2, A). Peak stresses occurred in the cells just below the commissure stents where the stent contacted the diseased aortic valve and was confined. Minimum principal stresses, which indicated the bending force on TAV stent, were $-44.4 \mathrm{MPa}$ and $-66.6 \mathrm{MPa}$ at 80 and $120 \mathrm{~mm} \mathrm{Hg}$, respectively (Figure 2, A). These stresses were similarly located in the cells just below the commissure stents, but also along the top of the stent in crossover points that met with the commissure struts.

Maximum principal stresses across the entire leaflet were $2.7 \mathrm{MPa}$ and $3.0 \mathrm{MPa}$ at 80 and $120 \mathrm{~mm} \mathrm{Hg}$, respectively (Figure 2, B, and Video 1). Peak stresses occurred at the upper leaflet edge where the leaflets were sutured to the stent at the commissures. Minimum principal stresses across the entire leaflet were $-0.5 \mathrm{MPa}$ and $-0.6 \mathrm{MPa}$ at 80 and $120 \mathrm{~mm} \mathrm{Hg}$, respectively. These stresses occurred at locations similar to maximum stresses: on the upper sutured edge of the leaflets close to the commissure (Figure 2, B). Upper sutured leaflet edges (region 1) contained maximum and minimum principal stresses for the entire leaflet assembly. Lower sutured leaflet edges (region 2) had the second highest peak stresses of 2.1 $\mathrm{MPa}$ and $2.6 \mathrm{MPa}$ at 80 and $120 \mathrm{~mm} \mathrm{Hg}$, respectively. Minimum principal stresses in region 2 were $-0.13 \mathrm{MPa}$ and $-0.14 \mathrm{MPa}$. Upper free leaflet edges (region 3) had maximum stresses of $1.1 \mathrm{MPa}$ and $1.5 \mathrm{MPa}$ at 80 and $120 \mathrm{~mm} \mathrm{Hg}$, respectively, and minimum stresses of $-0.18 \mathrm{MPa}$ and $-0.48 \mathrm{MPa}$ at 80 and $120 \mathrm{~mm} \mathrm{Hg}$, respectively. Lower leaflet belly (region 4) had slightly higher maximum principal stresses of $1.2 \mathrm{MPa}$ and 
Maximum Principal Stress
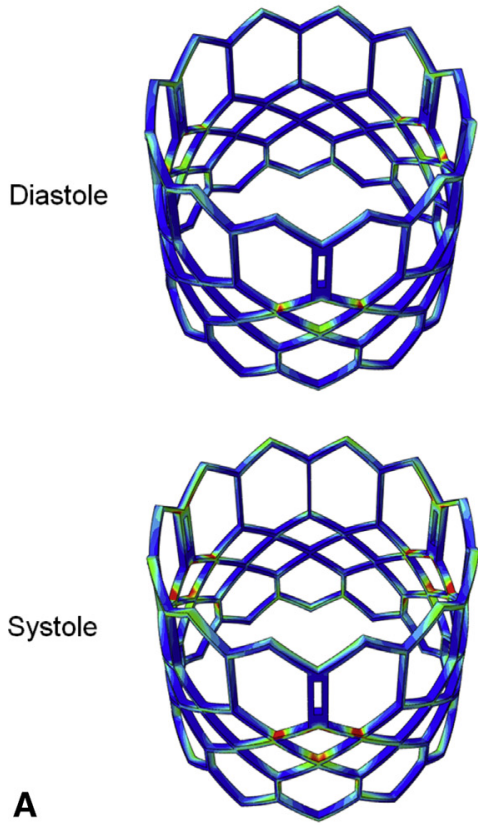

Maximum Principal Stress
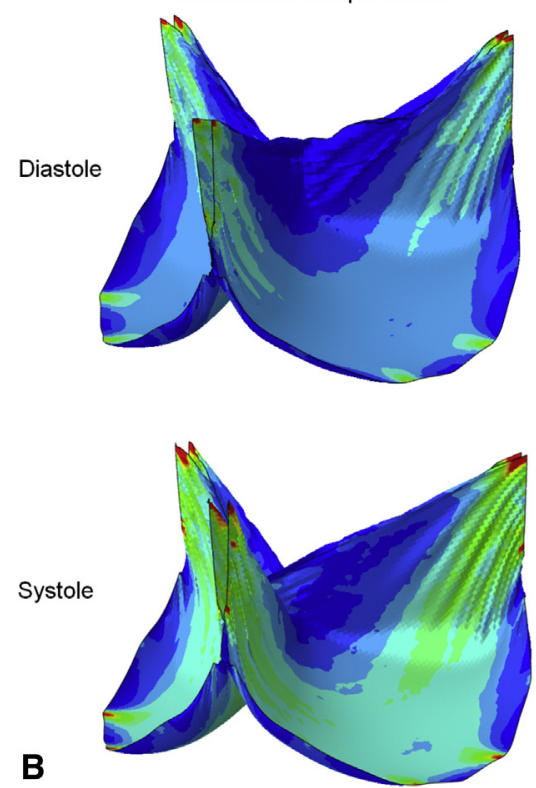

Minimum Principal Stress

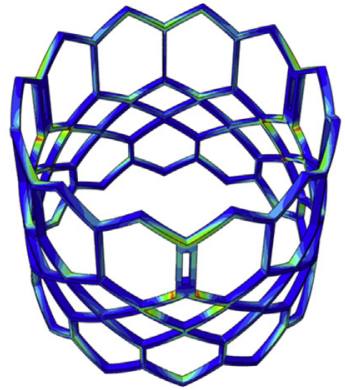

(a)

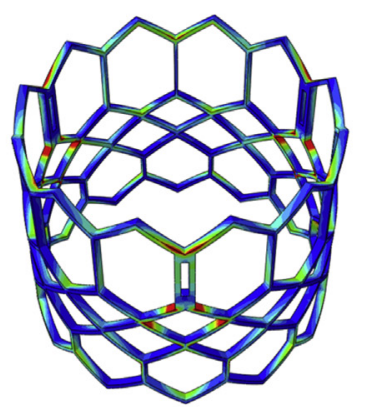

Minimum Principal Stress
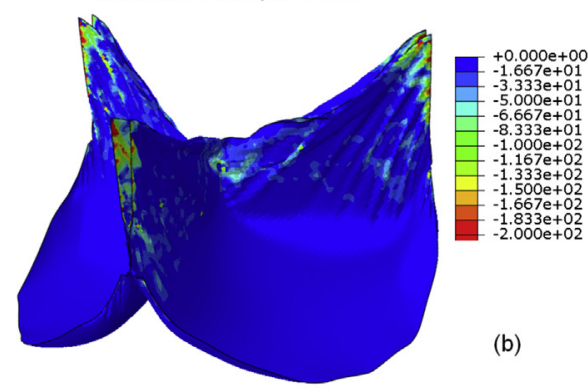

(b)

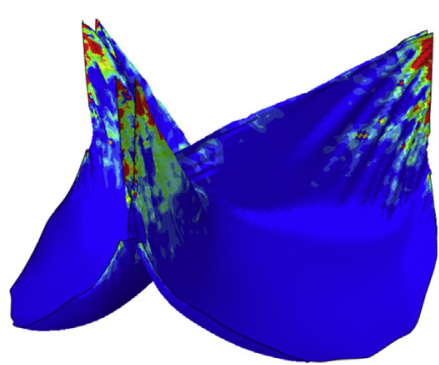

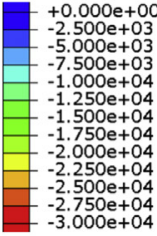

(b)

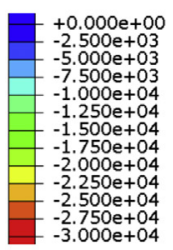

(d) (c)
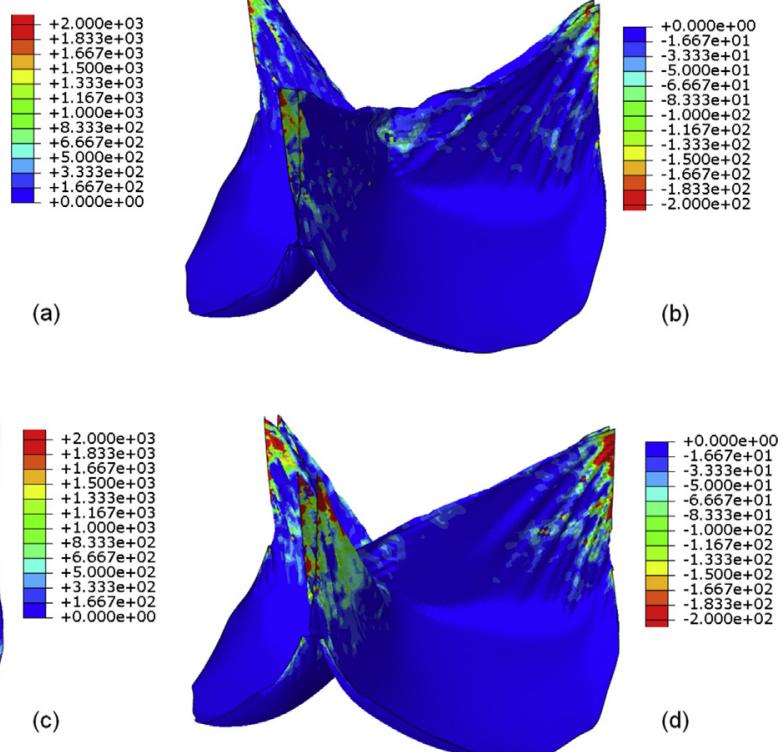

FIGURE 2. A, At $80 \mathrm{~mm} \mathrm{Hg}$ diastolic pressure, maximum (a) and minimum (b) principal stresses on the stent are shown. At $120 \mathrm{~mm} \mathrm{Hg}$ systolic pressure, maximum (c) and minimum (d) principal stresses are shown. B, At $80 \mathrm{~mm} \mathrm{Hg}$, maximum (a) and minimum (b) principal stresses on entire leaflet assembly are shown. At $120 \mathrm{~mm} \mathrm{Hg}$, maximum (c) and minimum (d) principal stresses on the entire leaflet are shown.

$1.7 \mathrm{MPa}$ at 80 and $120 \mathrm{~mm} \mathrm{Hg}$, respectively, than the upper leaflet region, but the magnitude of minimum principal stresses was lower $(-0.19$ and $-0.28 \mathrm{MPa}$ at 80 and $120 \mathrm{~mm} \mathrm{Hg}$, respectively).

Addition of the outer skirt varied stress distributions in the subregions, although none reached statistically significant differences compared with without the skirt (Figure 3, $P>.05)$. Without the sealing skirt, maximum principal stresses on the stent were reduced to $35.5 \mathrm{MPa}$ and $53.0 \mathrm{MPa}$ at 80 and $120 \mathrm{~mm} \mathrm{Hg}$, respectively, and minimum principal stresses were reduced to $-32.6 \mathrm{MPa}$ and $-48.6 \mathrm{MPa}$ at 80 and $120 \mathrm{~mm} \mathrm{Hg}$, respectively. In contrast, without the sealing skirt, maximum principal stresses on the leaflets occurred in the same regions of the upper commissure area but increased to $2.9 \mathrm{MPa}$ and 3.2 $\mathrm{MPa}$ at 80 and $120 \mathrm{~mm} \mathrm{Hg}$, respectively (Figure 3). 


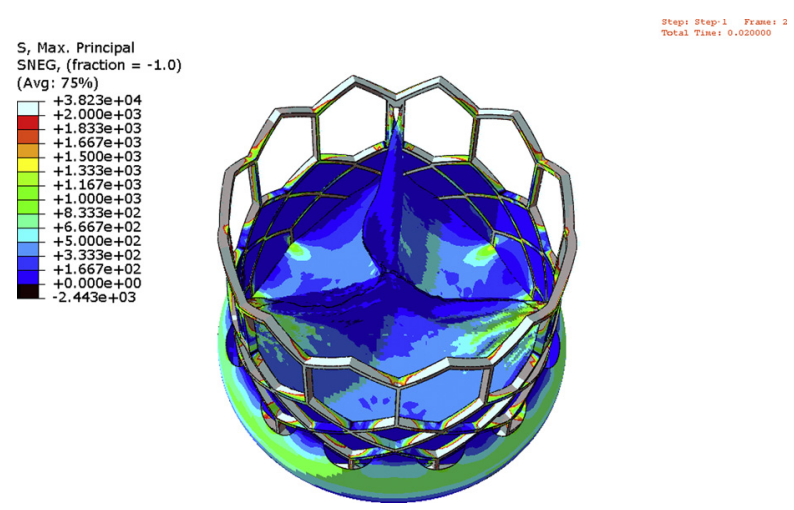

VIDEO 1. Maximum principal stress on the leaflet of the SAPIEN 3 valve (Edwards Lifesciences, Inc, Irvine, Calif) at diastole. Video available at: https://www.jtcvs.org/article/S0022-5223(18)31268-6/fulltext.

Minimum principal stresses on the leaflets decreased to $-0.38 \mathrm{MPa}$ and $-0.60 \mathrm{MPa}$ located at the upper commissural sutured edge at 80 and $120 \mathrm{~mm} \mathrm{Hg}$, respectively. In the lower commissural sutured edges, maximum principal stresses were $1.4 \mathrm{MPa}$ and $2.3 \mathrm{MPa}$, at 80 and $120 \mathrm{~mm} \mathrm{Hg}$, respectively, and minimum principal stresses were $-0.098 \mathrm{MPa}$ and $-0.10 \mathrm{MPa}$, at 80 and $120 \mathrm{~mm} \mathrm{Hg}$, respectively. Upper leaflet and lower belly

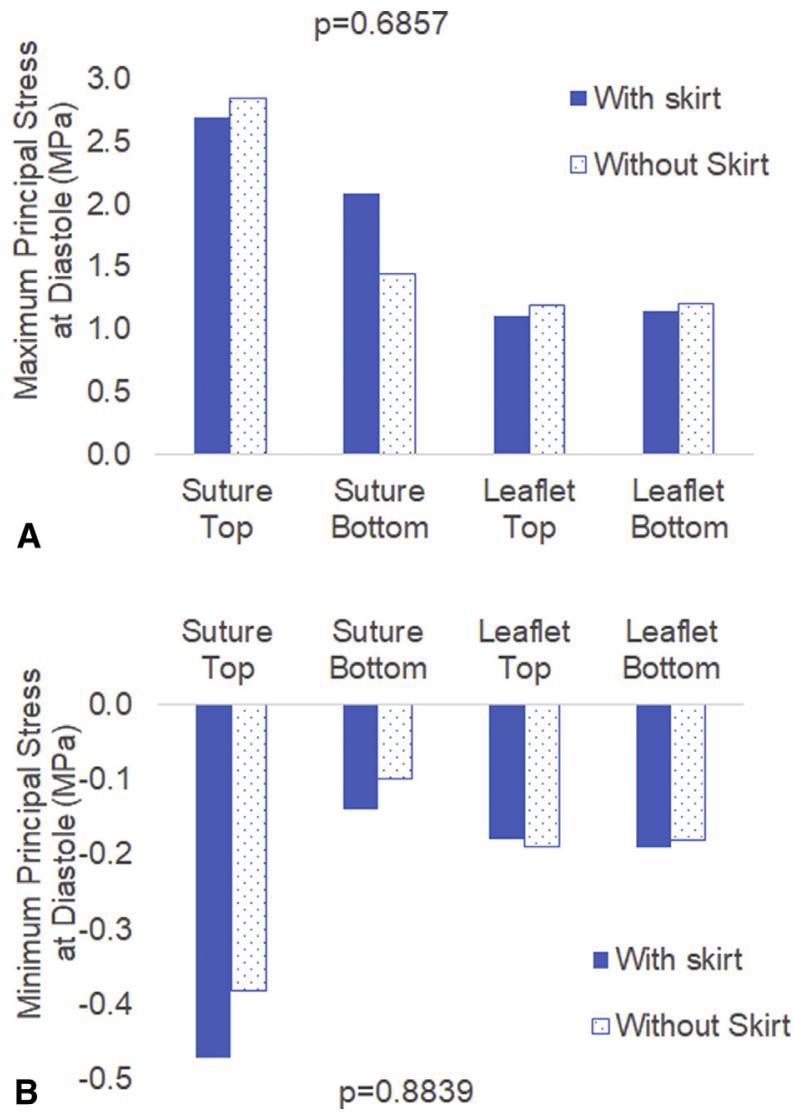

FIGURE 3. Comparison of (A) maximum principal stress and (B) minimum principal stress on different leaflet regions with and without the outer skirt at diastole.

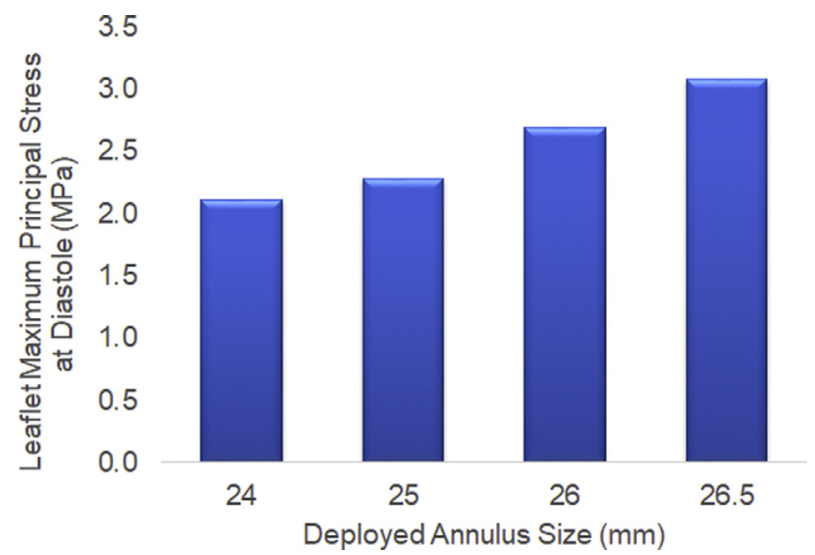

FIGURE 4. Comparison of maximum principal stress on leaflets within different deployed geometries of a 26-mm TAVR at diastole.

had less than half of maximum and minimum principal stresses compared with region 1.

TAVR is typically not deployed in the fully expanded nominal geometry; therefore, we simulated the underexpanded and overexpanded geometries in addition to nominal expansion. The deployed underexpanded geometry of $24 \mathrm{~mm}$ and $25 \mathrm{~mm}$ and the overexpanded geometry of $26.5 \mathrm{~mm}$ were studied. Peak leaflet stresses were $2.1 \mathrm{MPa}$ for $24 \mathrm{~mm}, 2.3 \mathrm{MPa}$ for $25 \mathrm{~mm}$, and $3.1 \mathrm{MPa}$ for $26.5 \mathrm{~mm}$, with increasing stresses with larger deployed geometries (Figure 4). Peak stresses and deformation were primarily observed in the commissure area in all the deployed geometries (Figure 5).

\section{DISCUSSION}

In this study, we demonstrated that for the stent of the 26-mm SAPIEN 3, maximum and minimum principal stresses occurred in the cells just below the commissural stent posts as well as the crosslinking stents that adjoined the commissure. For the leaflets, maximum and minimum principal stresses occurred at the commissures where the leaflets attached to the stent. From the durability perspective, leaflet as opposed to stent stresses is more critical, because the stent material is much stronger and less prone to fracture, whereas valve failure results from leaflet tearing or calcification. Maximum principal stress is the tension/tearing force, and minimum principal stress is the compression/bending force. Both stresses are of clinical importance because areas of high stress have been correlated as initiation sites for calcification and leaflet degeneration. ${ }^{12-15}$ High stress regions on the leaflets reflect areas that with hundreds of millions of cycles of opening and closing would be prone to initiating degeneration.

We previously examined stent and leaflet stresses in the earlier first- and second-generation balloon-expandable TAVs. However, notable design changes were implemented for the SAPIEN 3 compared with prior devices. An outer 
$24 \mathrm{~mm}$

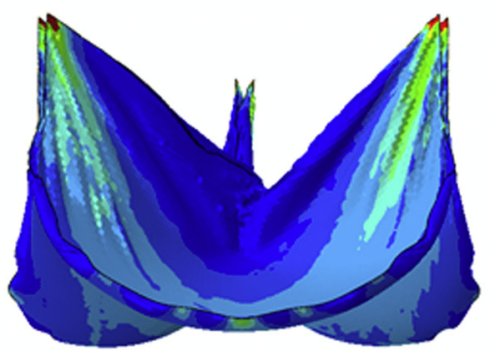

$26 \mathrm{~mm}$

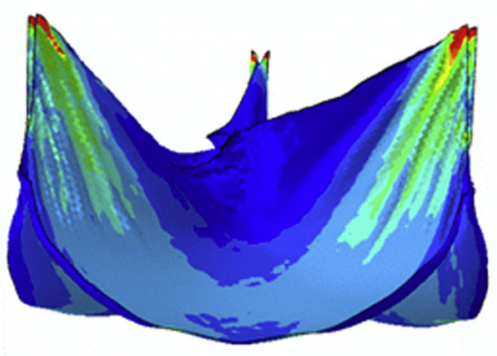

$25 \mathrm{~mm}$

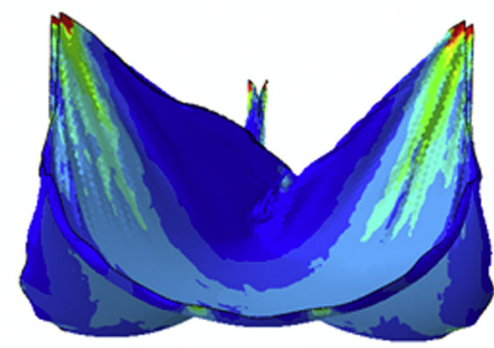

$26.5 \mathrm{~mm}$

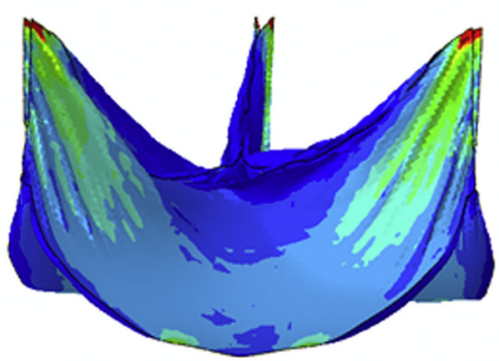

Max. Principal

FIGURE 5. Maximum principal stress distribution on leaflets within different deployed annulus sizes of TAVR at diastole.

PET sealing skirt was added to reduce PVL. Stent configuration was modified, which allowed a lower profile delivery system and easier access for percutaneous coronary interventions. Leaflet design also altered the configuration of the stent and leaflet interface at the commissures. Clinical results from the SAPIEN 3 at 1 year via the nested registry in the Placement of Aortic Transcatheter Valves II trial were excellent, with very low all-cause mortality and high overall survival $85.6 \%$ at 1 year. $^{20}$ With the outer sealing skirt, no severe PVL occurred and only a $2.7 \%$ rate of moderate PVL. With the reduction in delivery profile, transfemoral access rate was high, 84\%. Likewise, the SAPIEN Aortic Bioprosthesis European Outcome 3 registry at 1-year follow-up showed $98.3 \%$ success of implantation with $12.6 \%$ all-cause mortality at 1 year with $87.1 \%$ transfemoral access. Again, there was no severe PVL, and moderate PVL was low at $2.6 \% .^{21}$ For intermediate-risk patients, all-cause mortality at 1 year follow-up further declined with the SAPIEN 3 to $7.4 \%$ with moderate or severe PVL in $2 \%{ }^{22}$

\section{Outer Sealing Cuff and Paravalvular Leakage}

Moderate and severe PVL after TAVR are associated with increased mortality. ${ }^{5-9}$ To minimize post-TAVR PVL, an outer sealing skirt was added, which did exert effects on both stent and leaflet stresses albeit not statistically significantly. On the one hand, the skirt reduced leaflet peak stresses. Maximum principal stresses on the leaflet were decreased by $5.9 \%$ at $120 \mathrm{~mm} \mathrm{Hg}$ and $6.3 \%$ at $80 \mathrm{~mm} \mathrm{Hg}$. On the other hand, additional pressure on the skirt increased peak stresses on the stent. Maximum principal stresses on the stent increased by $7.19 \%$ at $120 \mathrm{~mm} \mathrm{Hg}$ and $8.73 \%$ at $80 \mathrm{~mm} \mathrm{Hg}$. From a durability perspective, the addition of an outer skirt appears to be beneficial by balancing out some of stresses on the leaflets. Nonetheless, peak stress levels clinically will be affected by TAVR shape after patient-specific deployment, based on deployed location and native valve calcification, which may negate some of these benefits.

\section{Comparison of Surgical Aortic Valve Replacement and Transcatheter Aortic Valve Replacement \\ Simulations}

Durability is the Achilles heel of bioprosthetic valves, whether TAVR or surgical aortic valve replacement (SAVR). Valve durability is influenced primarily by structural valve dysfunction, resulting from bioprosthetic valve degeneration. Pathologically, bioprosthetic degeneration involves leaflet cusp calcification and stiffening, and leaflet tearing. Recently, valve thrombosis has been highlighted as another potential mode of failure. ${ }^{23}$ For 
surgical bioprostheses, degeneration by calcification or leaflet tearing correlated with areas of high tensile and compressive stresses, ${ }^{11,24}$ and cyclic flexural fatigue and bending. ${ }^{10,25}$ Previously, the $25-\mathrm{mm}$ Edwards bovine pericardial valve was investigated by FEA, using leaflet material properties from those valves and exact valve geometry under $120 \mathrm{~mm} \mathrm{Hg}$ quasi-static loading conditions. ${ }^{11}$ Maximum in-plane stress ranged from 544.7 to $663.2 \mathrm{kPa}$; however, leaflet and stent interactions were not specifically described. Leaflet stresses were greatest near the commissures and least near the free edge. For surgical bioprostheses, FEA of high stress regions correlated well with sites of bioprosthetic leaflet calcification and degeneration. In our study, maximum principal stresses for the 26-mm SAPIEN 3 were significantly higher than reported for surgical bioprosthesis of comparable size. Differences in leaflet geometry and thickness may account for this. To crimp the SAPIEN 3 or other TAV designs into low-profile delivery systems, a thinner bovine or porcine pericardium is required. ${ }^{26}$ This leaflet thickness reduction translates to higher leaflet stresses, where stress is inversely proportional to leaflet thickness in an approximately linear fashion assuming similar material properties. Given that TAVR leaflets are approximately one half the thickness of SAVR leaflets, increased leaflet stress is to be expected. Increased TAVR rather than SAVR leaflet stresses may reflect an earlier tendency for degeneration, which should be closely followed clinically.

Computational TAV simulations that examined stress on leaflets have been limited. One recent study based on the 26-mm SAPIEN-XT reported average Von Mises stresses of the $1 \%$ of elements experiencing greatest stress to be $1.54 \mathrm{MPa}$ under $13 \mathrm{KPa}$ pressure in a patient-specific deployed model. ${ }^{27}$ However, the model was not based on exact leaflet geometry, but rather an estimate, and used the second-generation SAPIEN-XT. Maximum stress also was not reported. Another study with a homemade 23-mm TAV reported maximum principal stress of $2.5 \mathrm{MPa}^{28}$ in diastole, and another study reported maximum principal stress of $0.87 \mathrm{MPa}$ for a leaflet shape optimized from 500 designs and reported high stress regions in the leaflet belly. ${ }^{29}$ Neither study used exact geometry or a fully assembled TAV, including leaflets, stent, Dacron, skirt, and sutures, as in the current study. We examined maximum principal stresses of current third-generation, balloon-expandable SAPIEN 3 using exact leaflet geometry and thickness, and incorporated the stent, Dacron, and skirt with leaflet interactions in our simulations. In comparison with our prior work on the same-sized 26-mm Edwards SAPIEN, leaflet stresses in the SAPIEN $3(2.7 \mathrm{MPa})$ were slightly higher than in the first-generation design (2.5 MPa). Our leaflet stress results for SAPIEN 3 were also higher than those for the larger 29-mm SAPIEN-XT
(1.6 MPa). Compared with earlier generations, the SAPIEN 3 has a different design in how the leaflet is sutured to the stent at the commissure area. The first 2 generations of SAPIEN were sutured to a side bar along the radial direction, whereas the SAPIEN 3 is sutured to the circumferential bar on the stent and there are no radial side bars. In this manner, the suture moves away radially from the center of the valve. The leaflet configuration directly affects peak principal stresses and stress distribution. In general, stresses can be reduced by increasing leaflet thickness, aligning the material orientation, and optimizing leaflet shape computationally. ${ }^{26,30,31}$

The latest generation of valve design was optimized to meet pressing clinical needs of reducing PVL and lowering delivery system profile for transfemoral access. FEA stress analyses of surgical bioprostheses have shown correlation of high stress regions with sites of leaflet calcification initiation and degeneration. ${ }^{10,11,24,25}$ Our results suggest that for the SAPIEN 3, commissural leaflet regions will be most prone to leaflet degeneration, and given the higher stresses than surgical valves, the SAPIEN 3 may be prone to earlier degeneration. Presently, because the majority of TAVR recipients are elderly (average age 80 years), we have insufficient TAVR failure data to correlate stresses with degeneration. However, as TAVR moves to younger patients, whether low risk or intermediate risk, such durability data will be important to correlate with our stress analysis predictions.

\section{Study Limitations}

Our study did not take into account the crimping and ballooning process that occurs during TAVR. Crimping physically damages TAV leaflets and may weaken leaflets and increase leaflet stress. ${ }^{32,33}$ We did not destroy our TAV to test its leaflets for exact material properties given the rarity of obtaining TAVs and need for future TAV experimental in vitro tests. As such, we used excised leaflets from surgical bioprostheses to determine material properties for TAV leaflets. ${ }^{18}$ Although the treatment processes for both Edwards valves are expected to be the same, thinner pericardial leaflets used in TAVR may have different material properties than were represented here. The current model presents the stress on the initial implantation without the effect of degeneration over time and the material property changes. Progressive leaflet degeneration is expected to be localized and most likely starts from the locations with high stress concentrations as indicated in our current study. With more clinical evidence of TAVR leaflet degeneration, further work modeling containing time factor and material changes of degeneration would be beneficial. We studied only 1 commercial SAPIEN 3 valve because of limited availability of the clinical valve product for our research, which did not include additional sizes. The impact of valve size and 
deployment on the stent and leaflet stresses were beyond the scope of this study and may be included in future studies based on valve availability. We assumed strict standards with high reproducibility and quality controls during the manufacturing of these Food and Drug Administration-approved clinical TAVs by industry such that study of more samples would not yield statistically significant results. Our detailed FEA of SAPIEN 3 provides fundamental knowledge for future studies, such as valve-in-valve implantation or comparison of SAPIEN 3 with other TAVR designs, such as the Medtronic CoreValve (Minneapolis, Minn). Valve-in-valve implantation requires patient-specific geometry of the surgical valve and deployed geometry of SAPIEN 3 within with interactions are defined between the 2 valves, which is beyond the scope of the current study. Last, complex fluid-structure interaction simulations were not incorporated and beyond the present scope of this study.

\section{CONCLUSIONS}

We determined TAV stent and leaflet stresses on the 26-mm SAPIEN 3 using micro-computed tomography scanned geometry. We demonstrated that maximum stresses occurred at the cells of the stent just below the commissure and as the struts adjoined to the commissure, whereas for leaflets, maximum stresses occurred at the leaflet commissures where they attached to the stent. These leaflet regions will likely be areas where degeneration initiates. Future comparisons with surgical bioprostheses or other TAV devices will be necessary to compare relative durability based on valve design. Nevertheless, stress magnitude differences suggest higher stresses in the SAPIEN 3 relative to surgical bioprostheses, which may affect durability.

\section{Conflict of Interest Statement}

Dr Dvir serves as a consultant for Edward Life Sciences. Dr $\mathrm{Ge}$ is co-founder of ReValve Med, Inc, and reports grants from the National Institutes of Health during the conduct of the study. Dr Tseng is co-founder of ReValve Med, Inc, and reports grants from the National Institutes of Health during the conduct of the study. Dr Xuan reports grants from the American Heart Association for a postdoctoral fellowship during the conduct of this study. Dr Ye serves as a consultant for Edward Life Sciences. All other authors have nothing to disclose with regard to commercial support.

\section{References}

1. Leon MB, Smith CR, Mack MJ, Makkar RR, Svensson LG, Kodali SK, et al. Transcatheter or surgical aortic-valve replacement in intermediate-risk patients. N Engl J Med. 2016;374:1609-20.

2. Reardon MJ, Van Mieghem NM, Popma JJ, Kleiman NS, Sondergaard L, Mumtaz M, et al. Surgical or transcatheter aortic-valve replacement in intermediate-risk patients. N Engl J Med. 2017;376:1321-31.

3. Nishimura RA, Otto CM, Bonow RO, Carabello BA, Erwin JP III, Guyton RA, et al. 2014 AHA/ACC guideline for the management of patients with valvular heart disease: a report of the American College of Cardiology/ American Heart Association task force on practice guidelines. Circulation 2014;129:e521-643.

4. Ribeiro HB, Urena M, Allende R, Amat-Santos IJ, Rodes-Cabau J. Balloon-expandable prostheses for transcatheter aortic valve replacement. Prog Cardiovasc Dis. 2014;56:583-95.

5. Kapadia SR, Leon MB, Makkar RR, Tuzcu EM, Svensson LG, Kodali S, et al. 5 year outcomes of transcatheter aortic valve replacement compared with standard treatment for patients with inoperable aortic stenosis (PARTNER 1): a randomised controlled trial. Lancet. 2015;385:2485-91.

6. Mack MJ, Leon MB, Smith CR, Miller DC, Moses JW, Tuzcu EM, et al. 5-year outcomes of transcatheter aortic valve replacement or surgical aortic valve replacement for high surgical risk patients with aortic stenosis (PARTNER 1): a randomised controlled trial. Lancet. 2015;385:2477-84.

7. Barbanti M, Petronio AS, Ettori F, Latib A, Bedogni F, De Marco F, et al. 5-year outcomes after transcatheter aortic valve implantation with CoreValve prosthesis. JACC Cardiovasc Interv. 2015;8:1084-91.

8. Reardon MJ, Adams DH, Kleiman NS, Yakubov SJ, Coselli JS, Deeb GM, et al. 2-year outcomes in patients undergoing surgical or self-expanding transcatheter aortic valve replacement. J Am Coll Cardiol. 2015;66:113-21.

9. Yakubov SJ, Adams DH, Watson DR, Reardon MJ, Kleiman NS, Heimansohn D, et al. 2-year outcomes after iliofemoral self-expanding transcatheter aortic valve replacement in patients with severe aortic stenosis deemed extreme risk for surgery. J Am Coll Cardiol. 2015;66:1327-34.

10. Martin C, Sun W. Simulation of long-term fatigue damage in bioprosthetic heart valves: effects of leaflet and stent elastic properties. Biomech Model Mechanobiol. 2014;13:759-70.

11. Sun W, Abad A, Sacks MS. Simulated bioprosthetic heart valve deformation under quasi-static loading. J Biomech Eng. 2005;127:905-14.

12. Sabbah HN, Hamid MS, Stein PD. Mechanical factors in the degeneration of porcine bioprosthetic valves: an overview. J Card Surg. 1989;4:302-9.

13. Thubrikar MJ, Deck JD, Aouad J, Nolan SP. Role of mechanical stress in calcification of aortic bioprosthetic valves. J Thorac Cardiovasc Surg. 1983;86:115-25.

14. Dvir D, Bourguignon T, Otto CM, Hahn RT, Rosenhek R, Webb JG, et al. Standardized definition of structural valve degeneration for surgical and transcatheter bioprosthetic aortic valves. Circulation. 2018;137:388-99.

15. Rodriguez-Gabella T, Voisine P, Puri R, Pibarot P, Rodes-Cabau J. Aortic bioprosthetic valve durability: incidence, mechanisms, predictors, and management of surgical and transcatheter valve degeneration. J Am Coll Cardiol. 2017;70:1013-28.

16. Xuan Y, Krishnan K, Ye J, Dvir D, Guccione JM, Ge L, et al. Stent and leafle stresses in 29-mm second-generation balloon-expandable transcatheter aortic valve. Ann Thorac Surg. 2017;104:773-81.

17. Xuan Y, Krishnan K, Ye J, Dvir D, Guccione JM, Ge L, et al. Stent and leaflet stresses in a 26-mm first-generation balloon-expandable transcatheter aortic valve. J Thorac Cardiovasc Surg. 2017;153:1065-73.

18. Kuang H, Xuan Y, Lu M, Mookhoek A, Wisneski AD, Guccione JM, et al. Leaflet mechanical properties of Carpentier-Edwards Perimount Magna pericardial aortic bioprostheses. J Heart Valve Dis. 2017;26:81-9.

19. Azadani AN, Chitsaz S, Matthews PB, Jaussaud N, Leung J, Tsinman T, et al Comparison of mechanical properties of human ascending aorta and aortic sinuses. Ann Thorac Surg. 2012;93:87-94.

20. Herrmann HC, Thourani VH, Kodali SK, Makkar RR, Szeto WY, Anwaruddin S et al. One-year clinical outcomes with SAPIEN 3 transcatheter aortic valve replacement in high-risk and inoperable patients with severe aortic stenosis. Circulation. 2016;134:130-40.

21. Wendler O, Schymik G, Treede H, Baumgartner H, Dumonteil N, Neumann FJ, et al. SOURCE 3: 1-year outcomes post-transcatheter aortic valve implantation using the latest generation of the balloon-expandable transcatheter heart valve. Eur Heart J. 2017:38:2717-26.

22. Thourani VH, Kodali S, Makkar RR, Herrmann HC, Williams M, Babaliaros V, et al. Transcatheter aortic valve replacement versus surgical valve replacement in intermediate-risk patients: a propensity score analysis. Lancet. 2016;387: 2218-25.

23. Makkar RR, Fontana G, Jilaihawi H, Chakravarty T, Kofoed KF, de Backer O, et al. Possible subclinical leaflet thrombosis in bioprosthetic aortic valves. $N$ Engl J Med. 2015;373:2015-24.

24. Vesely I. The evolution of bioprosthetic heart valve design and its impact on durability. Cardiovasc Pathol. 2003;12:277-86.

25. Kim H, Lu J, Sacks MS, Chandran KB. Dynamic simulation of bioprosthetic heart valves using a stress resultant shell model. Ann Biomed Eng. 2008;36:262-75. 
26. Li K, Sun W. Simulated thin pericardial bioprosthetic valve leaflet deformation under static pressure-only loading conditions: implications for percutaneous valves. Ann Biomed Eng. 2010;38:2690-701.

27. Bailey J, Curzen N, Bressloff NW. The impact of imperfect frame deployment and rotational orientation on stress within the prosthetic leaflets during transcatheter aortic valve implantation. J Biomech. 2017; $53: 22-8$.

28. Abbasi M, Azadani AN. Leaflet stress and strain distributions following incomplete transcatheter aortic valve expansion. J Biomech. 2015;48: 3663-71.

29. Li K, Sun W. Simulated transcatheter aortic valve deformation: a parametric study on the impact of leaflet geometry on valve peak stress. Int J Numer Method Biomed Eng. 2017;33.
30. Moe RE, Ryder JK. Altering heart valve leaflet attachment geometry to influence the location and magnitude of maximum loaded stress on the leaflet. In: Patent US, ed. Vol. 6,613,086. US: Carbomedics Inc; 2003.

31. Cao H, Sun W, inventors; Edwards Lifesciences Corp, assignee. Virtual heart valve. US patent 8219 229. July 12, 2012.

32. Kiefer P, Gruenwald F, Kempfert J, et al. Crimping may affect the durability of transcatheter valves: an experimental analysis. Ann Thorac Surg. 2011;92:155-60.

33. Alavi SH, Groves EM, Kheradvar A. The effects of transcatheter valve crimping on pericardial leaflets. Ann Thorac Surg. 2014;97:1260-6.

Key Words: transcatheter aortic valve, leaflet, stress, durability

Readers who found these articles interesting may also like to read the following papers found in recent and future issues of our sister publications, Seminars in Thoracic and Cardiovascular Surgery and Operative Techniques in Thoracic and Cardiovascular Surgery!

\section{Adult: Aortic Valve}

ORIGINAL SUBMISSION: Single Dose Del Nido Cardioplegia in Minimally Invasive Aortic Valve Surgery. Daniel Ziazadeh. Semin Thoracic Surg 2017: 471-476

Editorial Commentary: Is “As Good” Good Enough? James I. Fann. Semin Thoracic Surg 2017: 477-478

ORIGINAL SUBMISSION: Aortic Root Reconstruction and Valve Repair During Acute Type A Aortic Dissection Repair. Jared P. Beller. Oper Tech Thorac Cardiovasc 2017: 80-90

ORIGINAL SUBMISSION: Repair of the Bicuspid Aortic Valve. Ulrich Schneider. Oper Tech Thorac Cardiovasc 2017: $91-109$ 